\title{
Distribution of the glutamate transporters GLT-1 (SLC1A2) and GLAST (SLC1A3) in peripheral organs
}

Accepted: 26 June 2006/Published online: 26 July 2006

(C) Springer-Verlag 2006

\begin{abstract}
The glutamate transporters GLT-1 and GLAST are widely expressed in astrocytes in the brain where they fulfill important functions during glutamatergic neurotransmission. The present study examines their distribution in peripheral organs using in situ hybridization (ISH) and immunocytochemistry. GLAST was found to be more widely distributed than GLT-1. GLAST was expressed primarily in epithelial cells, cells of the macrophage-lineage, lymphocytes, fat cells, interstitial cells, and salivary gland acini. GLT-1 was primarily expressed in glandular tissue, including mammary gland, lacrimal gland, and ducts and acini in salivary glands, but also by perivenous hepatocytes and follicular dendritic cells in spleen and lymph nodes. The findings demonstrate that, although expressed by the same cells in the brain, these two glutamate transporters have different distribution patterns in peripheral tissues and that they fulfill glutamate transport functions apart from glutamatergic neurotransmission in these areas.
\end{abstract}

Keywords Glutamate - Transport - Peripheral organs · Kidney $\cdot$ Liver $\cdot$ Macrophage

\section{Introduction}

The GLT-1 (SLC1A2, also known as EAAT2) and GLAST (SLC1A3, also known as EAAT1) are two widely expressed glutamate transporters in the brain.

U. V. Berger · M. A. Hediger

Membrane Biology Program and Renal Division,

Brigham and Women's Hospital, Boston, MA 02115, USA

Present address: U. V. Berger

UB-In Situ, Natick, MA 01760, USA

E-mail: uberger@ubinsitu.com

Present address: M. A. Hediger ( $\square)$

Institute of Biochemistry and Molecular Medicine,

University of Berne, Bühlstrasse 28, 3012 Bern, Switzerland

E-mail: matthias.hediger@mci.unibe.ch

Fax: + 41-31-6313410
They belong to the "solute carrier 1" (SLC1) family of solute transporters that also include the glutamate transporters EAAC1 (SLC1A1 also known as EAAT3), EAAT4 (SLC1A6), and EAAT5 (SLC1A7), as well as the "system ASC" amino acid transporters, called ASCT1 (SLC1A4) and ASCT2 (SLC1A5) (for a recent review, see Kanai and Hediger 2004). GLT-1 and GLAST remove glutamate from the brain extracellular fluid through co-transport of one glutamate molecule with three sodium ions and one proton ion, as well as the counter-transport of one potassium ion (Kanai and Hediger 2004). Responsible for most of the glutamate uptake in the brain, they fulfill a crucial role in glutamatergic neurotransmission by removing glutamate from the synaptic cleft and keeping extracellular glutamate below neurotoxic levels. Originally, GLT-1 and GLAST expressions had both been localized to astrocytes in the brain (Kanai and Hediger 2004). GLAST is most strongly expressed in the Bergmann glia, whereas GLT-1 is strongest in astrocytes in cerebral cortex and hippocampus. However, most astrocytes express both transporters, and their protein localization on the plasma membrane is similar (Kanai and Hediger 2004).

More recent studies indicate that there is expression of these two glutamate transporters beyond astrocytes. For example, GLT-1 mRNA and protein have been found in subgroups of neurons in forebrain, and a current theory is that GLT-1 represents the long-sought presynaptic glutamate transporter that removes glutamate from the synaptic cleft after release (Chen et al. 2004). GLT-1 is also expressed in a select group of tanycytes in the third ventricle, as well as in pineal and pituitary gland (Berger and Hediger 2001). GLAST expression has been demonstrated in ependymal cells, in circumventricular organs such as the subfornical organ and the organum vasculosum of the lamina terminalis, as well as in the meninges and the pituitary gland (Berger and Hediger 2000).

When GLT-1 and GLAST were first isolated, initial Northern analyses indicated a primary expression only in the central nervous system. However, more detailed 
studies have uncovered that GLT-1 and GLAST expressions are by far not restricted to the central nervous system alone. GLAST expression has previously been reported in the cochlea, pituitary gland, placenta, pancreas, breast, and bone, whereas, GLT-1 expression has been described in placenta, pancreas, bone, liver, muscle, ovary, testis, and kidney (Tanaka 1993; Arriza et al. 1994; Kawakami et al. 1994; Kirschner et al. 1994; Li et al. 1994; Shashidharan et al. 1994; Furness and Lehre 1997; Mason et al. 1997; Utsunomiya-Tate et al. 1997; Martinez-Lopez et al. 1998; Matthews et al. 1998; Redecker and Pabst 2000; Howell et al. 2001; Furness et al. 2002; Howell et al. 2003; Redecker et al. 2003; Mason 2004). Most of these studies presented evidence for expression of GLT-1 and GLAST using Northern blotting or PCR reactions. When anatomical analysis using immunostaining was performed, such as in placenta, bone, or testis (Mason et al. 1997; Matthews et al. 1998; Redecker et al. 2003), the localizations of GLT-1 and GLAST were not associated with nerve terminals, suggesting that GLT-1 and GLAST fulfill additional roles in these peripheral organs, most likely related to the use of transported glutamate for metabolic purposes. In the present study, we have performed an indepth analysis of the distribution of GLT-1 and GLAST outside the brain to identify the areas and cell types that express these transporters in the periphery. Adjacent sections were hybridized to mRNA probes for GLT-1 and GLAST and processed for non-isotopic in situ hybridization (ISH). Once the expression of mRNA was established in specific cell types, immunostaining for GLT-1 and GLAST was performed to demonstrate the presence of glutamate transporter protein.

\section{Materials and methods}

\section{Animals}

Male and female Sprague-Dawley rats (200-250 g, three per gender) from Takoma Farms were used for this study. The animals were housed in the animal care facility on site prior to the collection of the tissues. This research was approved by the Brigham and Women's Hospital Institutional Animal Care and Use Committee and fully conforms to the "Principles of Laboratory Animal Care of the National Institutes of Health" (NIH publication no. 86-23, revised 1985). All results presented were observed in at least three independent experiments.

\section{Tissue preparation}

Rats were anesthetized with an i.p. injection of pentobarbital $(50-100 \mathrm{mg} / \mathrm{kg})$ and then sacrificed by decapitation. Organs (liver, kidney, thymus, salivary glands, testis, prostate, urethra, spleen, ovaries, urinary bladder, tongue, lymph nodes, heart, and mammary glands) were dissected and immediately frozen by placing in dry-ice cooled isopentane at $-30^{\circ} \mathrm{C}$. Organs were stored in $50 \mathrm{ml}$ tubes in the $-80^{\circ} \mathrm{C}$ freezer for 1 week to 3 months before they were sectioned in a Leica cryostat at $10 \mu \mathrm{m}$ thickness. Sections were placed on Superfrost Plus microscope slides (Fisher, Atlanta, GA, USA), and the slides were stored in a slide box in the $-20^{\circ} \mathrm{C}$ freezer for 1 day to 3 months before processing.

\section{In situ hybridization}

Non-isotopic ISH was performed using digoxigenin-labeled cRNA probes and alkaline phosphatase detection as described (Berger and Hediger 1998). The microscope slides with the unfixed sections were adjusted to room temperature for $5 \mathrm{~min}$, and then fixed in freshly prepared, ice-cold $4 \%$ paraformaldehyde in $0.1 \mathrm{M}$ phosphate buffer ( $\mathrm{pH}$ 7.4) for $15 \mathrm{~min}$ by immersion. Slides were washed three times for $5 \mathrm{~min}$ in $0.1 \mathrm{M}$ phosphatebuffered saline, and then acetylated by immersing in $1.4 \%$ triethanolamine (Sigma, St Louis, MO, USA) to which acetic anhydride was added to $0.5 \%$ followed by stirring for $10 \mathrm{~min}$. Hybridization was performed in slide mailers by total immersion in hybridization buffer that contained $50 \%$ formamide, $5 \times$ single-strength citrate (SSC), 2\% blocking reagent (Roche Applied Science, Indianapolis, IN, USA), $0.02 \%$ SDS, $0.1 \%$ sarcosine, and approximately $100 \mathrm{ng} / \mathrm{ml}$ of cRNA probe. Sections were hybridized at $68^{\circ} \mathrm{C}$ over $72 \mathrm{~h}$ with probes against rat GLT-1 (1.6 kb, nucleotides 136-1,763 of the Kanner clone) or against rat GLAST $(1.8 \mathrm{~kb}$, nucleotides 58-1,900 of a PCR fragment, Berger and Hediger 2000). Washing steps included incubations in $2 \times \mathrm{SSC}$ and $0.2 \times \mathrm{SSC}$ at $68^{\circ} \mathrm{C}$. Sections were incubated at room temperature in $1 \%$ blocking reagent in maleic acid buffer, then in alkaline phosphatase-conjugated anti-digoxigenin Fab fragments (1:5,000 dilution, $1 \mathrm{~h}$, Roche), and developed for 18 or $42 \mathrm{~h}$ with BCIP/ NBT substrate (Kierkegard and Perry Laboratories, Gaithersburg, MD, USA). Sections were rinsed several times in $100 \mathrm{mM}$ Tris, $150 \mathrm{mM} \mathrm{NaCl}, 20 \mathrm{mM}$ EDTA pH 9.5, and coverslipped with glycerol gelatin (Sigma). Control sections were incubated in an identical concentration of the sense probe transcript. Photographs were taken using a Nikon E600 microscope and a SPOT digital camera. Image plates were assembled using Adobe Photoshop 6.0 software on a Macintosh ibook $600 \mathrm{mHz}$. All results presented were observed in at least three independent experiments.

Immunohistochemistry

Immunostaining was performed on frozen sections that were adjacent to those used for ISH, using peptidepurified rabbit antibodies against GLAST (anti-A522, antibody no. 141, animal number 68488, August 24, 
1995) and GLT-1 (anti-B12, antibody no. 291, animal number 26970, February 3, 1998) (Haugeto et al. 1996). The antibodies were provided by Dr. N.C. Danbolt, University of Oslo, Norway. Slides carrying the frozen sections were adjusted to room temperature for $5 \mathrm{~min}$ and then fixed in neutral buffered $10 \%$ formalin at room temperature for $15 \mathrm{~min}$ (Sigma). Slides were then incubated in blocking solution $(1 \%$ normal goat serum, $0.1 \%$ triton X-100 in $20 \mathrm{mM}$ phosphate-buffered saline) for $1 \mathrm{~h}$, before they were incubated with the GLAST or GLT-1 antisera at a dilution of 1:2,000 in blocking solution overnight $(18 \mathrm{~h})$ at room temperature. Following three washes for $5 \mathrm{~min}$ each, bound antibodies were visualized through incubation for $2 \mathrm{~h}$ at room temperature with a CY3-conjugated goat anti-rabbit secondary antibody (1:200, Jackson ImmunoResearch Laboratories, West Grove, PA, USA, catalog no. 111-165-003) in 1\% normal goat serum in phosphate-buffered saline. Subsequently, slides were washed three times for $15 \mathrm{~min}$ each in phosphate-buffered saline and then coverslipped using Vectamount (Vector Laboratories, Burlingame, CA, USA). Controls included incubation without primary antibodies. Photographs were taken using a Nikon E600 microscope and a SPOT digital camera, and assembled using Adobe Photoshop 6.0 software on a Mac ibook $600 \mathrm{MHz}$.

\section{Results}

The specificities of the GLT-1 and GLAST RNA probes used have been established in several previous studies. They produce distinct labeling patterns in the brain (Berger and Hediger 1998, 2000, 2001) as well as in peripheral organs. In most tissues, one probe served as a control for the other since GLT-1 and GLAST were mostly localized to different cell types. The specificities of the GLT-1 and GLAST antibodies used in this study have also been demonstrated previously (Lehre et al. 1995). Antibodies against both transporters produced selective staining in numerous tissues and cell types. The GLAST staining differed in all cases from the GLT-1 staining, demonstrating that the secondary antibody did not produce any background. Because of the large amount of data, we decided to present results as pictures only where signals for both the mRNA and the protein for one or both transporters could be demonstrated. In some tissues, signals could only be shown with either in situ labeling or immunostaining, but not both. This is likely due to a lack of detection sensitivity either for the in situ detection or the immunostaining. However, since only one type of GLAST or GLT-1 antiserum was used in this study, the possibility cannot be ruled out that any immunostaining observed without concurrent in situ labeling may represent a cross-reaction with another unknown antigen.

The results for the GLT-1 and GLAST ISH and immunostaining are presented in Figs. 1, 2, 3, 4, and 5 and summarized in Table 1. In most Figures, GLAST
mRNA labeling and GLAST protein staining are shown in columns 1 and 2, respectively, and GLT-1 mRNA labeling and GLT-1 protein staining are shown in columns 3 and 4. Most rows show adjacent sections of the same tissue. In general, GLAST mRNA and protein was found to be widely expressed in peripheral tissues in a number of epithelia and some other specific cell types. In contrast, GLT-1 mRNA and protein expression was found in fewer tissues and usually not in epitheliaforming cells. Whereas GLAST and GLT-1 may be expressed in the same organ, they are usually localized to different cell types.

\section{Epithelia}

Strong epithelial expression of GLAST mRNA and protein was observed in tongue, kidney, urinary bladder, ovary, prostate gland, and urethra. In the tongue, GLAST mRNA (Fig. 1a) and protein (Fig. 1b) was restricted to the basal cell layer of the epithelium outlining membranes (insert in Fig. 1b), suggesting a membranous localization. GLT-1 message could not be demonstrated in tongue (Fig. 1c). However, a relatively faint GLT-1 immunosignal was present in the epithelium more superficial to where the GLAST signal was localized (Fig. 1d). At the light microscope level, this immunosignal appeared relatively diffuse, making its precise cellular localization unclear. Since no GLT-1 mRNA could be detected at the same location, the GLT-1 immunostaining in the tongue epithelium may be non-specific.

In the kidney, GLAST mRNA and protein were found in the transitional surface epithelium of the renal pelvis (Fig. 1e, f) and in the macula densa portion of the distal convoluted tubules (Fig. 1i, j). Again, the immunostaining highlighted the membranes of the epithelial cells (insert in Fig. 1f). No significant expression of GLT-1 mRNA or protein staining was detected in the transitional epithelium (Fig. 1g, h). GLT-1 protein, but not mRNA, staining was observed in the glomeruli (Fig. 1k, 1). However, the intensity of this glomerular GLT-1 staining was markedly higher than the GLT-1 staining in other organs, making it likely that it represents crossreactivity with another unrelated protein. The transitional epithelium is continuous with the lining of the ureter and the lining of the urinary bladder. Consistent with this, the GLAST mRNA and protein staining was also present in the epithelium in urinary bladder (Fig. 1m, n). Again, the protein immunostaining outlined the membrane of the epithelial cells, primarily in the basal cell layer. No GLT-1 mRNA or protein labeling was seen in urinary bladder (Fig. 1o, p).

In the ovary, GLAST mRNA and protein labeling was detected in the epithelia of corpus luteum, as well as in theca cells in various stages of development (Fig. 2a, $\mathrm{b}, \mathrm{e}, \mathrm{f})$. Also, GLAST immunostaining was apparent in the germinal surface epithelium covering the ovary (Fig. 2b). No GLT-1 mRNA or protein labeling was 

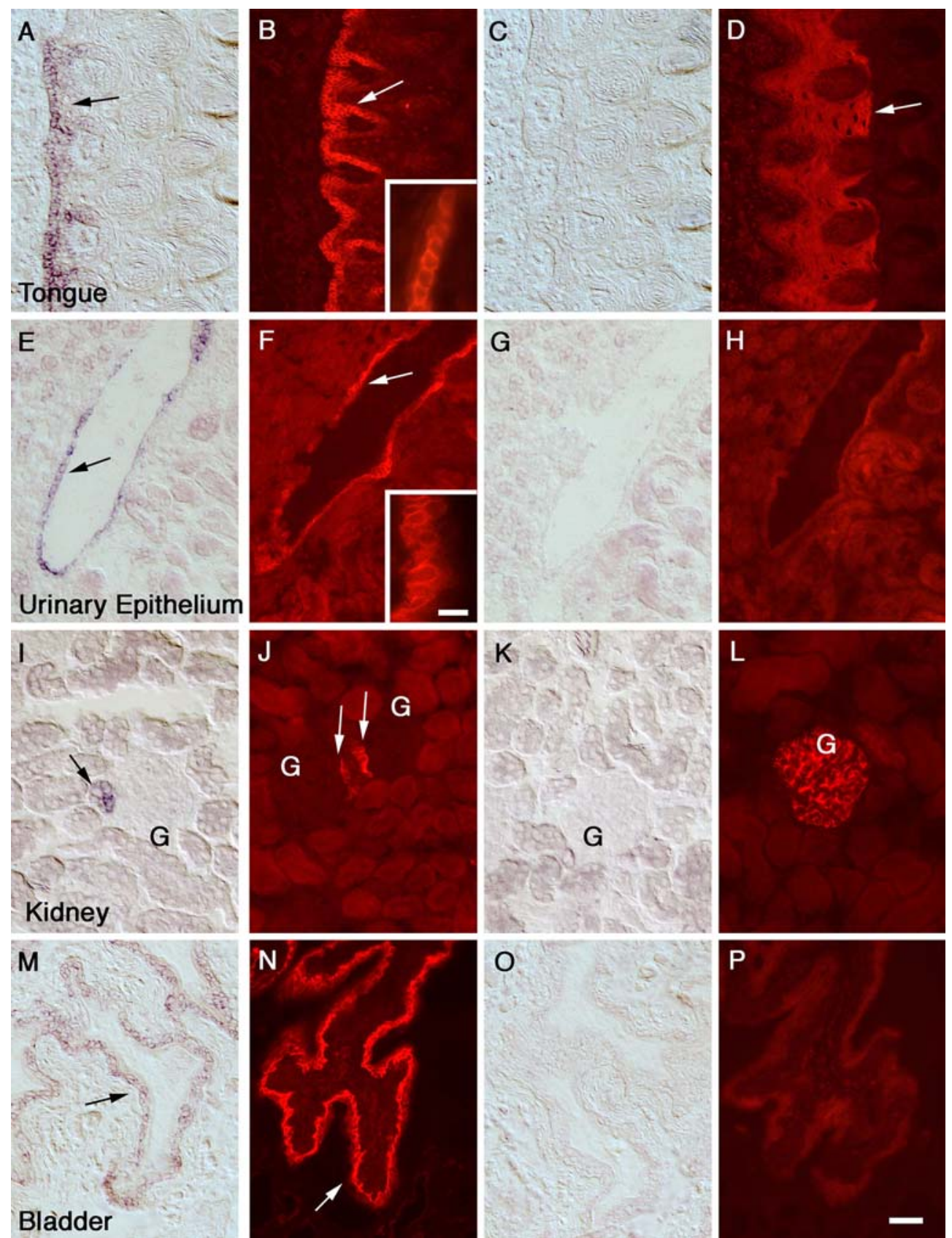

Fig. 1 In situ hybridization analysis of mRNA expression (first and third columns) and immunocytochemical analysis of protein expression (second and fourth columns) for GLAST (left two columns) and GLT-1 (right two columns) in the tongue (a-d), in the transitional surface epithelium of kidney $(\mathbf{e}-\mathbf{h})$, in kidney cortex near glomeruli (i-l), and in the urinary bladder $(\mathbf{a}-\mathbf{d}, \mathbf{m}-\mathbf{p})$. GLAST mRNA and protein is expressed by cells in the basal layer of the tongue epithelium (arrows, a, b). The insert in b shows the membrane staining at higher magnification. GLT-1 mRNA was not found in tongue (c), but a weak GLT-1 protein staining was apparent in the epithelium more superficial to the GLAST labeled

observed in the ovary (Fig. 2c, d, g, h). In the prostate gland, GLAST mRNA and protein were present in the epithelial cell layer (Fig. 2i, j). The GLAST immunostaining clearly outlined the lateral and basal membranes and was fainter in the apical membranes. The

cells (arrow, d). In kidney, GLAST expression was found in the transitional surface epithelium of the renal pelvis (arrows, e, $\mathbf{f}$, and insert in $\mathbf{f}$ ) and in the macula densa portion of thick ascending limbs (arrows, $\mathbf{i}, \mathbf{j}, \mathbf{g}$ : glomeruli). No GLT-1 labeling was seen in the surface epithelium $(\mathbf{g}, \mathbf{h})$. Glomeruli (g and $\mathbf{~})$ were strongly stained for GLT-1, but showed no GLT-1 mRNA labeling (k). The basal cell layer in urinary bladder epithelium showed mRNA and protein labeling for GLAST but not GLT-1 (m-p, only epithelium and subepithelial connective tissues are shown). Magnification bars: $50 \mu \mathrm{m}$

basal lamina was also immunopositive. No mRNA labeling for GLT-1 was observed in the prostate epithelium (Fig. 2k), but the basal lamina between the epithelial layers was immunopositive as well (Fig. 21). The basal lamina staining was not observed in controls 

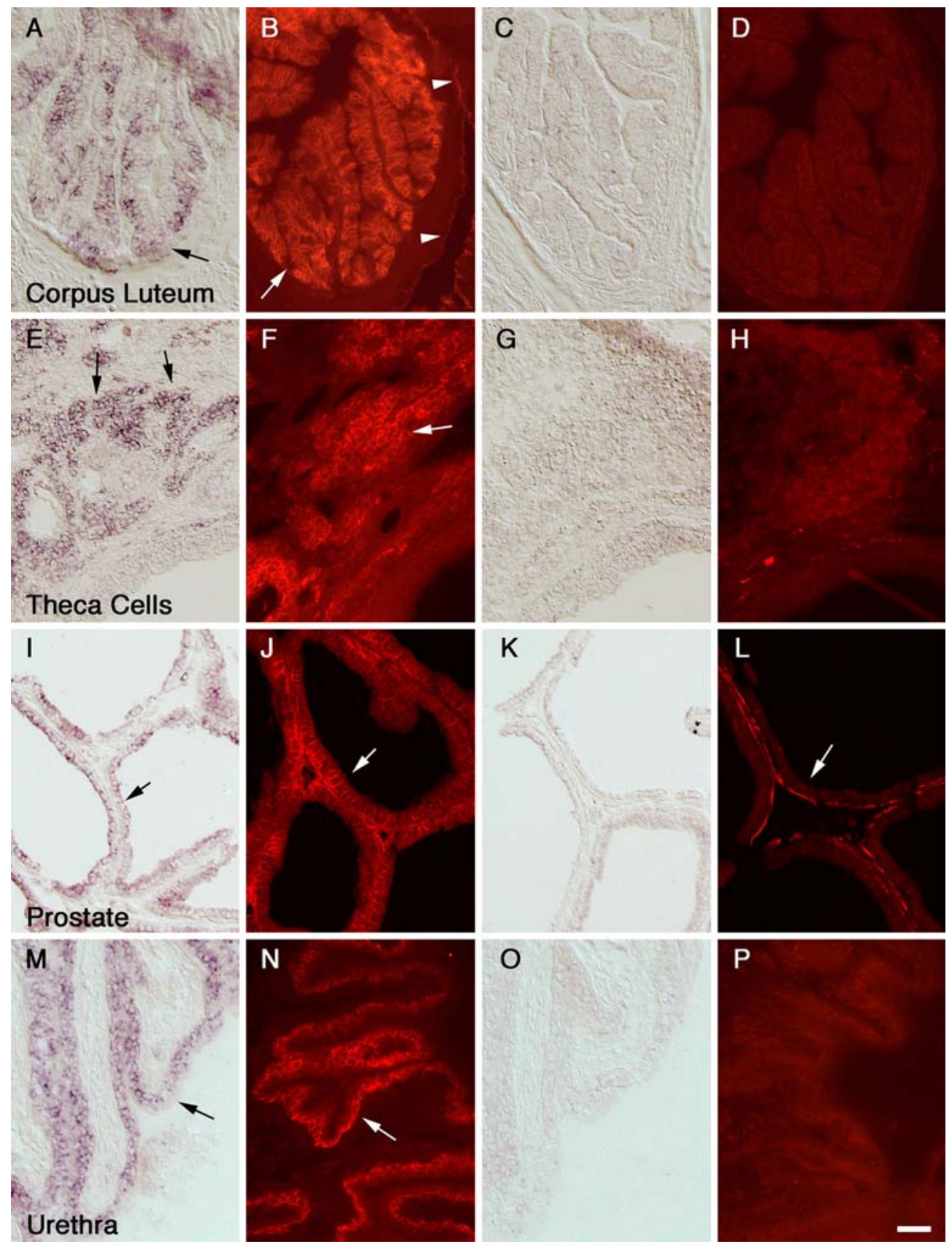

Fig. 2 In situ hybridization analysis of mRNA expression (first and third columns) and immunocytochemical analysis of protein expression (second and fourth columns) for GLAST (left two columns) and GLT-1 (right two columns) in the corpus luteum of ovary $(\mathbf{a}-\mathbf{d})$, and the theca cells of ovary $(\mathbf{e}-\mathbf{h})$, the prostate $(\mathbf{i}-\mathbf{l})$, and the urethra $(\mathbf{m}-\mathbf{p})$. In the ovary, GLAST mRNA and protein labeling was found in the epithelium of corpus luteum (arrows, a, b). The surface membrane of the ovary also showed positive GLAST immunostaining (arrowheads, b) Theca cells in the ovary were positively labeled for GLAST mRNA and protein (arrows, e,

without primary antibody, but the lack of GLT1 mRNA labeling suggests potential non-specific labeling. The epithelium of the prostatic urethra is also labeled for GLAST mRNA and GLAST protein (Fig. 2m, n), but not GLT-1 mRNA or protein (Fig. 2o, p). f). No GLT-1 labeling was found in the ovary. GLAST mRNA and protein was expressed in the epithelial cell layer of the prostate (arrows, $\mathbf{i}, \mathbf{j}$ ) and the prostatic urethra (arrows, m, n). In urinary bladder and urethra, the basal cell layer of the epithelium was GLAST-positive. In prostate, the GLAST protein staining appeared basolateral (j). No GLT-1 mRNA or protein labeling was found in the epithelia of prostate or urethra $(\mathbf{k}, \mathbf{l}, \mathbf{o}, \mathbf{p})$. Only the basal lamina below the epithelial cell layer in prostate was immuno-positive for GLT-1 (arrow, l). Magnification bar: $50 \mu \mathrm{m}$

\section{Lymphatic organs}

Both GLAST and GLT-1 mRNA and protein labeling was observed in lymphatic organs such as spleen, lymph nodes, and thymus. In thymus, strong GLAST mRNA 

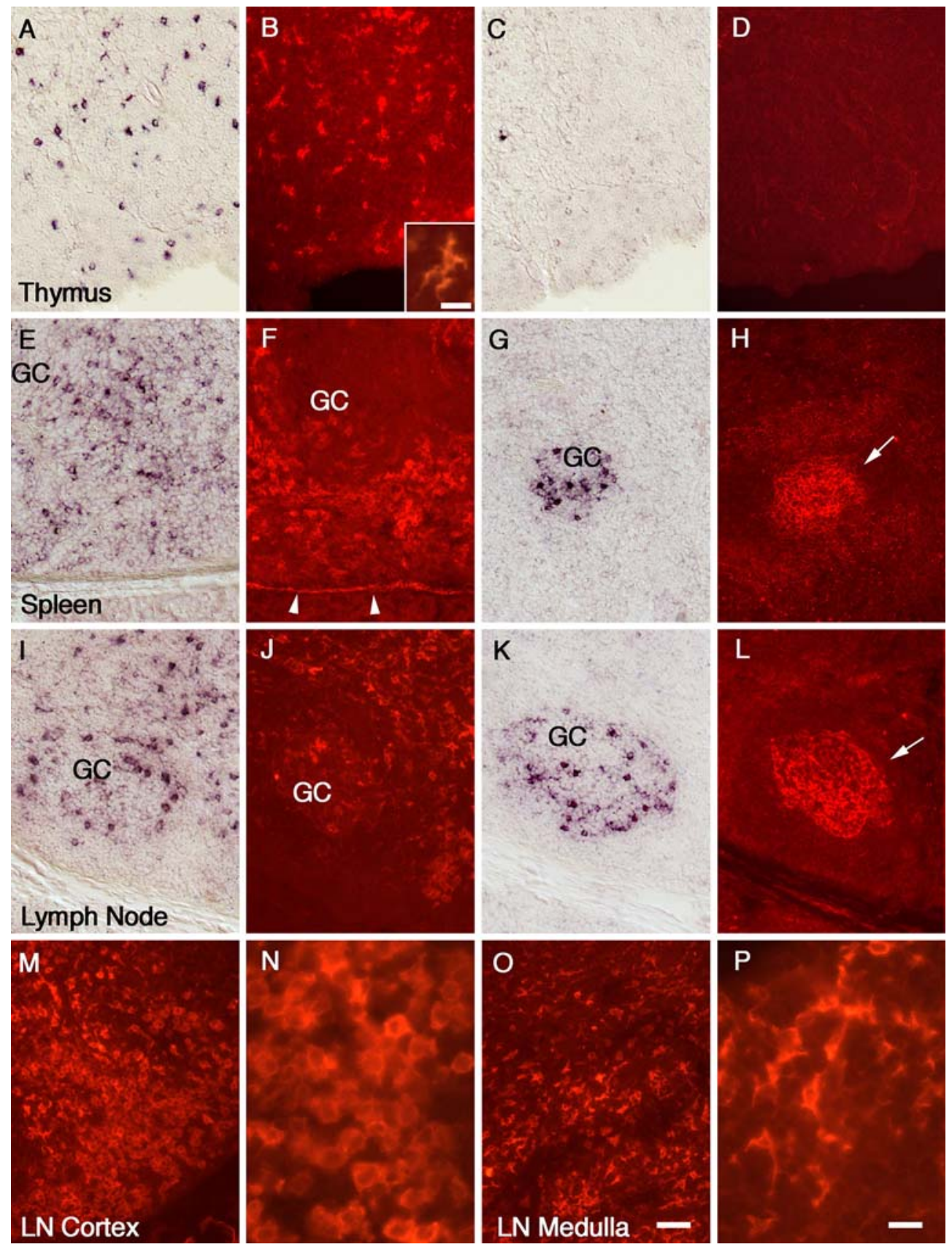

Fig. 3 In situ hybridization analysis of mRNA expression (a, c, e, $\mathbf{g}, \mathbf{i}, \mathbf{k})$ and immunocytochemical analysis of protein expression (b, $\mathbf{d}, \mathbf{f}, \mathbf{h}, \mathbf{j}, \mathbf{l}, \mathbf{m}-\mathbf{p})$ for GLAST $(\mathbf{a}, \mathbf{b}, \mathbf{e}, \mathbf{f}, \mathbf{i}, \mathbf{j}, \mathbf{m}-\mathbf{p})$ and GLT-1 (c, $\mathbf{d}, \mathbf{g}$, $\mathbf{h}, \mathbf{k}, \mathbf{l})$ in the thymus $(\mathbf{a}-\mathbf{d})$, the spleen $(\mathbf{e}-\mathbf{h})$, and a lymph node near the salivary glands $(\mathbf{i}-\mathbf{l}, \mathbf{m}-\mathbf{p})$. GLAST mRNA and protein labeling was found in scattered dendritic cells in thymus cortex and medulla (a, b, insert in b). No labeling for GLT-1 was discerned in the thymus. In the spleen, GLAST mRNA and protein staining was widespread in red pulp, and more restricted in the germinal centers of white pulp $(G C)$. GLAST immunostaining was also apparent in the surface membrane covering the spleen (arrowheads, f). GLT-1 mRNA and protein labeling was present in follicular dendritic cells

and protein labeling was present in cells scattered throughout cortex and medulla (Fig. 3a, b). Based on their dendritic shape, these GLAST-positive cells are likely antigen-presenting cells (insert in Fig. 3b). No

in the germinal centers (arrow, g, h). In lymph node, GLAST mRNA and protein staining was also widespread in cortex and medulla areas, and more restricted in the germinal centers $(G C)$ (i, j). Some areas of cortex showed widespread immunostaining of cells that appeared cuboidal in shape ( $\mathbf{m}$, and at higher magnification in $\mathbf{n}$ ), suggesting they are lymphocytes. Other areas of cortex showed very little labeling (not shown). In the medulla, the GLAST-positive cells appeared dendritic in shape (o, and higher magnification in p), suggesting antigen-presenting cells. Magnification bars: $50 \mu \mathrm{m}$ for all pictures except insert in $\mathbf{b}, \mathbf{m}$, and $\mathbf{n}$, $15 \mu \mathrm{m}$ for insert in $\mathbf{b}, \mathbf{m}$, and $\mathbf{n}$

clear GLT-1 mRNA labeling or protein staining was distinguished in thymus (Fig. 3c, d).

In the spleen, GLAST mRNA labeling and protein immunostaining was widespread in red pulp and more 

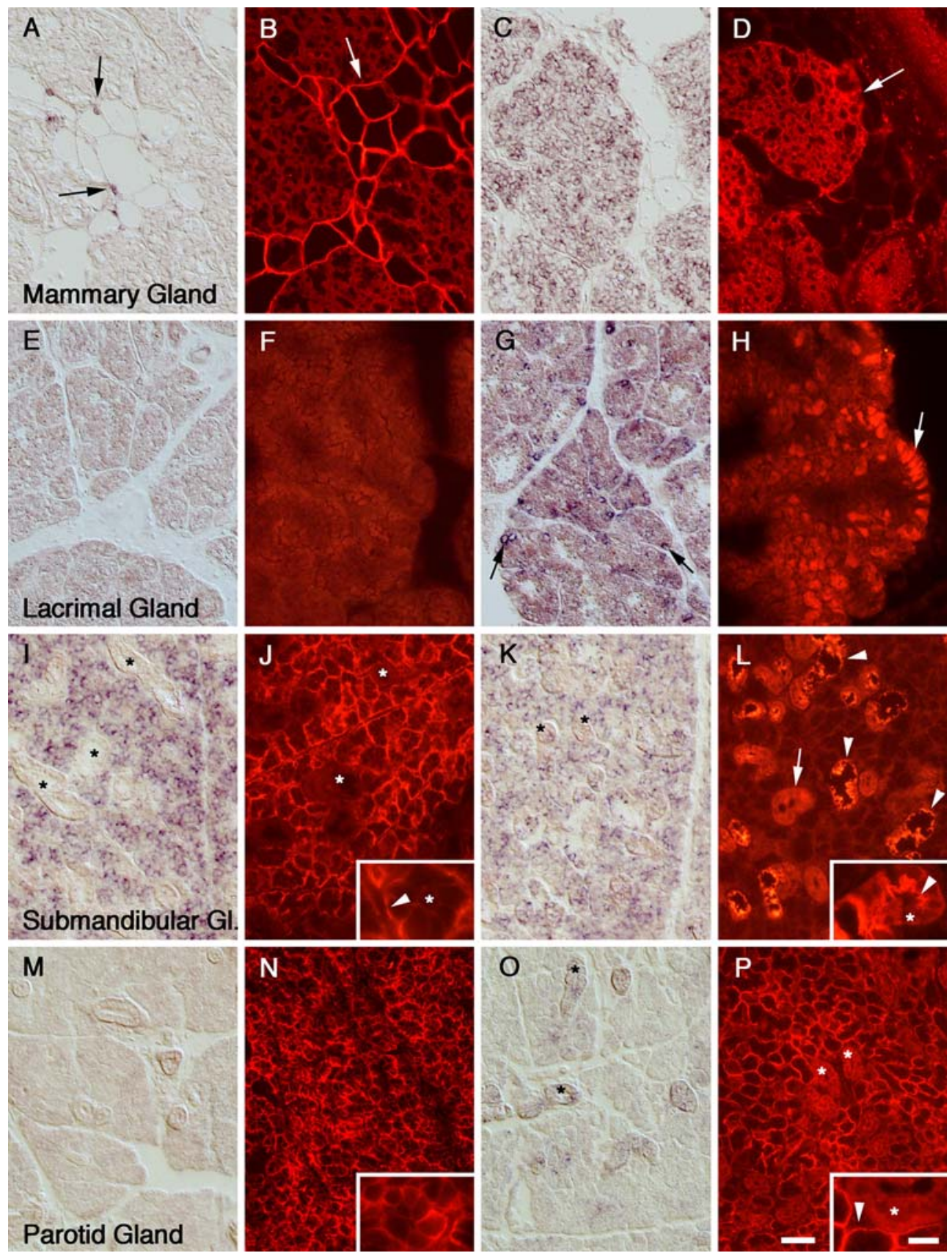

Fig. 4 In situ hybridization analysis of mRNA expression (first and third columns) and immunocytochemical analysis of protein expression (second and fourth columns) for GLAST (left two columns) and GLT-1 (right two columns) in the mammary gland (a-d), the intraorbital lacrimal gland $(\mathbf{e}-\mathbf{h})$, the submandibular salivary gland $(\mathbf{i}-\mathbf{l})$, and the parotid salivary gland $(\mathbf{m}-\mathbf{n})$. In the mammary gland, GLAST mRNA is expressed in scattered interstitial cells (arrows, a) that form a reticular network which is stained by the GLAST antiserum (arrow, b). GLT-1 mRNA and protein labeling is expressed in the glandular cells $(\mathbf{c}, \mathbf{d})$. In the lacrimal gland, no labeling for GLAST mRNA or protein was found $(\mathbf{e}, \mathbf{f})$. In contrast, the secretory lacrimal gland cells express GLT-1 mRNA (arrows, g) and GLT-1 protein (arrow, h). In the submandibular gland, GLAST mRNA (i) and GLAST protein (j) is expressed by acini but not by striated (arrowheads) or granular (arrows) ducts $(\mathbf{i}, \mathbf{j})$. The GLAST staining is localized to the basolateral membranes of the acini (j, and arrowhead in insert in $\mathbf{j}$, asterisks: lumen of acinus). Weak GLT-1 mRNA labeling is found

in acini and striated (arrowheads) and granular (arrows) ducts (k). However, GLT-1 protein staining was only pronounced in the ducts (I). Granular ducts showed intense staining of the luminal surface (arrows), whereas, staining of striated ducts was moderate, and present both on membranes and in the cytoplasm (arrowheads). The insert in $\mathbf{I}$ shows a higher magnification of a granular duct with pronounced surface staining (arrowhead), the asterisks point to cytoplasmic staining of the duct cells. In the parotid gland, no appreciable GLAST mRNA labeling was present (m); yet, GLAST protein staining of basolateral membranes was widespread (n, and insert in n, asterisks: acinus lumen, arrowhead: stained acinus membrane). Weak GLT-1 mRNA labeling was present in the ducts of parotid gland (asterisks, o), but no labeling was observed in the acini. GLT-1 protein staining was found in both ducts (asterisks, $\mathbf{p}$ ) and in the acini (p). The insert in $\mathbf{p}$ shows a higher magnification of a striated duct (asterisks) and the stained basal acinus membranes (arrowhead). Magnification bars: 50 and $15 \mu \mathrm{m}$ for inserted pictures 


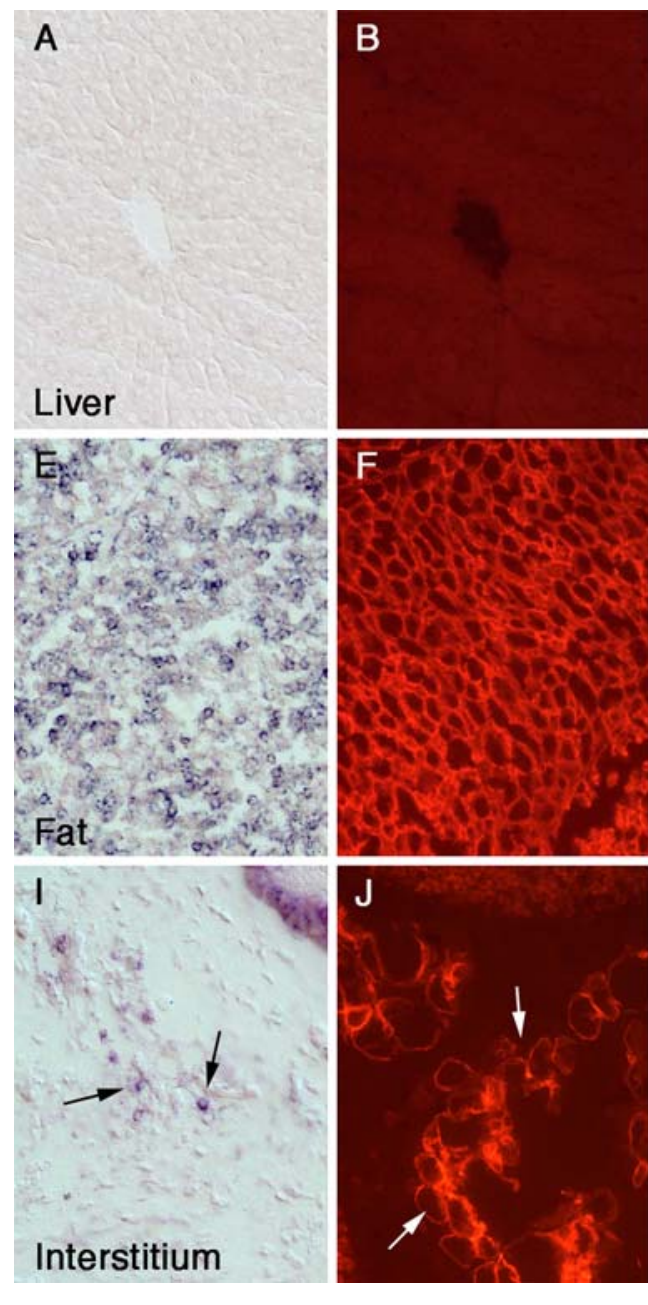

Fig. 5 In situ hybridization analysis of mRNA expression (first and third columns) and immunocytochemical analysis of protein expression (second and fourth columns) for GLAST (left two columns) and GLT-1 (right two columns) in the liver (a-d), in adipose cells from a fat pad near kidney medulla (e-h), and in interstitial connective tissue near salivary glands (i-l). GLAST expression was not observed in liver $(\mathbf{a}, \mathbf{b})$ apart from some interstitial cells near blood vessels (not shown). In contrast, GLT-1

restricted in white pulp (Fig. 3e, f). The shape of the GLAST-positive cells was again dendritic. The GLAST antibody also stained the surface membrane of the spleen (Fig. 3f). GLT-1 mRNA labeling was present in a cluster of cells in the germinal centers within the white pulp (Fig. 3g). Likewise, GLT-1 immunostaining was primarily restricted to the cells in the germinal center (Fig. 3h).

A very similar labeling pattern was seen in salivary gland lymph nodes: widespread labeling for GLAST in cortex and medulla, and relatively restricted labeling for GLT-1 in germinal centers (Fig. 3i-1).

GLAST mRNA and protein appeared to be localized in more than one cell type of the lymph node. In the bottom row of Fig. 3, low and high power views of GLAST immunostaining in lymph node cortex (Fig. $3 \mathrm{~m}, \mathrm{n}$ ) and medulla (Fig. 3o, p) are shown. In
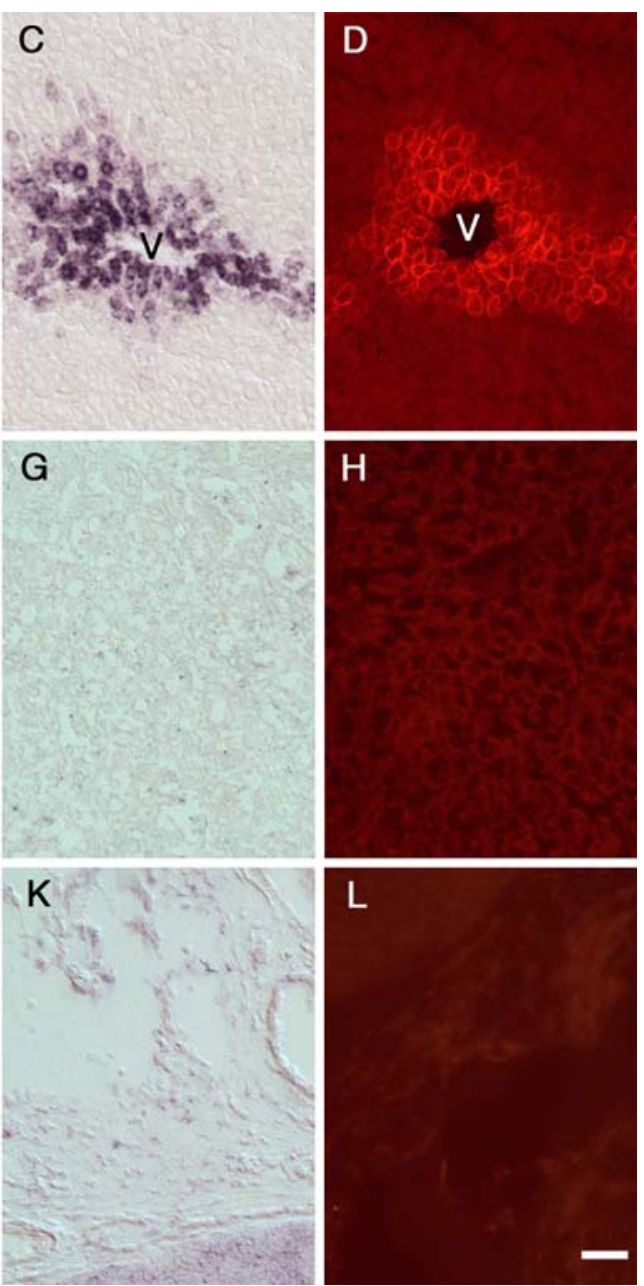

mRNA and protein were strongly expressed by perivenous hepatocytes (c, d, v: vein). GLAST mRNA and protein was expressed by adipose cells in a fat pad near kidney medulla $(\mathbf{e}, \mathbf{f})$ whereas GLT-1 was not $(\mathbf{g}, \mathbf{h})$. GLAST mRNA and protein labeling was observed in interstitial cells in connective tissue [from salivary gland complex (arrows, i, j)]. No GLT-1 labeling was present in interstitial tissue $(\mathbf{k}, \mathbf{l})$. Magnification bar: $50 \mu \mathrm{m}$

certain parts of the cortex, GLAST was expressed in a great number of cells (Fig. 3m, n), while in other parts of the cortex, GLAST was expressed only in a few cells (not shown), suggesting GLAST expression in certain lymphocytes. In medullary areas, GLAST positive cells were somewhat less abundant and had a different morphology. In comparison to the relatively cuboidal appearance of GLAST positive cells in cortex (Fig. $3 \mathrm{~m}, \mathrm{n}$ ), the scattered GLAST positive cells in the medulla had more dendrites (Fig. 3o, p), suggesting antigen-presenting cells.

\section{Glands}

Glandular tissues such as mammary gland, orbital lacrimal gland, and salivary glands expressed both GLAST 
Table 1 Summary of results found in peripheral tissues using in situ hybridization $(I S H)$ and immunofluorescence $(I F)$ for GLAST and GLAST

\begin{tabular}{|c|c|c|c|c|}
\hline & \multicolumn{2}{|c|}{ GLAST } & \multicolumn{2}{|c|}{ GLT1 } \\
\hline & ISH & IF & ISH & IF \\
\hline \multicolumn{5}{|l|}{ Epithelia } \\
\hline Tongue & + & + & - & \pm \\
\hline Kidney, surface epithelium & + & + & - & - \\
\hline Macula densa & + & + & - & - \\
\hline Bladder & + & + & - & - \\
\hline Ovary & + & + & - & - \\
\hline Prostate gland & + & + & - & - \\
\hline Urethra & + & + & - & - \\
\hline \multicolumn{5}{|l|}{ Lymphatics } \\
\hline Thymus & + & + & - & \pm \\
\hline Spleen, red pulp & + & + & - & - \\
\hline White pulp & + & + & - & - \\
\hline Germinal center & + & + & + & + \\
\hline $\begin{array}{l}\text { Lymph node, cortex, } \\
\text { and medulla }\end{array}$ & + & + & - & - \\
\hline Germinal center & + & + & + & + \\
\hline \multicolumn{5}{|l|}{ Glands } \\
\hline Mammary, epithelium & - & - & + & + \\
\hline Connective tissue cells & + & + & - & - \\
\hline Submandibular, acini & + & + & + & - \\
\hline Ducts & - & - & + & + \\
\hline Parotid, acini & - & + & + & + \\
\hline Ducts & - & - & - & + \\
\hline Lacrimal & - & - & + & + \\
\hline Liver, hepatocytes & - & - & + & + \\
\hline Fat cells & + & + & - & - \\
\hline Connective tissue cells & + & + & - & - \\
\hline $\begin{array}{l}\text { Capsular membranes (heart, } \\
\text { ovary, and spleen) }\end{array}$ & - & + & - & - \\
\hline
\end{tabular}

\pm Denotes presence or absence of staining or labeling. Note widespread expression of GLAST in epithelia and lymphatic tissues and of GLT-1 in glandular tissue

and GLT-1 transporters, but in different cell types. In the mammary gland (Fig. 4a), GLAST mRNA labeling was observed in connective tissue cells in between the tubuloalveolar glands. These cells form a network of fibers that is strongly immunopositive for GLAST (Fig. 4b). In contrast, GLT-1 mRNA and protein expression is found in the epithelial cells of the alveolar glands (Fig. 4c, d).

In the orbital lacrimal gland, GLAST mRNA or protein labeling was not found (Fig. 4e, f). GLT-1 mRNA and protein, however, were present in the secreting cells (Fig. 4g, h). The GLT-1 immunostaining appeared cytoplasmatic at the light microscope level.

In the salivary glands, both GLAST and GLT-1 expression were observed. In the submandibular gland, weak GLAST mRNA labeling was present in the secretory acini, but not in the striated or granular ducts (Fig. 4i). GLAST immunostaining highlighted the basolateral membranes of the acini and was absent in ducts (Fig. 4j). The insert in Fig. 4j highlights the basolateral acinar GLAST staining. GLT-1 mRNA labeling was also relatively weak and was observed in acini, striated and granular ducts (Fig. 4k). GLT-1 protein staining was strongest in the luminal surface of the granular ducts (arrowheads, Fig. 4l, and insert in 41). Less intense GLT-1 staining was also seen in striated ducts (arrows, Fig. 4l), but no clear signals were found in the acini membranes.

In the parotid gland, no GLAST mRNA labeling could be detected (Fig. 4m), but GLAST immunostaining was present in the acini membranes (Fig. 4n). Again, the GLAST immunostaining was most pronounced in the basolateral membranes of the acini (insert in Fig. 4n). Weak GLT-1 mRNA labeling was found in parotid gland ducts, but no labeling appeared present in the acini (Fig. 4o). GLT-1 immunostaining, in contrast, was present in the striated ducts, and also in the abluminal membrane of the acini (Fig. 4p). The insert in Fig. 4p highlights the GLT-1 staining in striated ducts (asterisks), and in the acini membrane (arrowhead).

\section{Other organs}

In the liver, no GLAST mRNA or protein labeling was found in hepatocytes (Fig. 5a, b). In contrast, strong GLT-1 mRNA and protein labeling was found in perivenous hepatocytes (Fig. 5c, d). The GLT-1 antiserum labeled the membranes of the hepatocytes. A few cells were positive for GLAST mRNA and protein in interstitial tissue such as around major blood vessels in liver (not shown).

Strong GLAST mRNA and protein staining was found in fat cells, such as in the adipose tissue near the kidney papilla (Fig. 5e, f) or other areas. The antiserum staining outlined the membranes of the adipose cells. No GLT-1 labeling was found in these fat cells (Fig. 5g, h).

Positive labeling for GLAST mRNA and protein was also observed in interstitial cells in connective tissue surrounding salivary glands (Fig. 5i, j). Similar to the labeled cells in the mammary gland, GLAST mRNA labeling was restricted to the cytoplasm near the nucleus, whereas the GLAST protein staining was widely present in the network fibers produced by these cells (Fig. 5j). No GLT-1 labeling was present in these interstitial cells (Fig. 5i, j).

\section{Discussion}

The present study identifies the cellular distribution patterns for the glutamate transporters GLT-1 and GLAST in peripheral tissues. In most tissues analyzed, previous studies had not performed anatomical localization of the transporter expression. Interestingly, GLT1 and GLAST are both expressed by the same astrocytic cells in the central nervous system (Kanai and Hediger 2004), but they appeared to be rarely co-localized in the same cells in the periphery. GLAST expression was most often seen in epithelial cells such as in the tongue, urinary bladder, ovaries, prostate gland, and urethra. In 
contrast, GLT-1 expression was observed primarily in glandular tissue, including mammary glands, salivary glands, and lacrimal glands. Furthermore, GLAST expression was also found in dendritic cells and lymphocytes of lymphoid organs, and interstitial cells and fat cells throughout the body. GLT-1, on the other hand, was found also in perivenous hepatocytes in liver and in a distinct group of dendritic cells in spleen and lymph node.

In contrast to the brain, where GLAST and GLT-1 are crucial players in glutamatergic neurotransmission, GLAST and GLT-1 expressions in the peripheral organs may play a role in glutamate uptake for metabolic purposes or in the conversion of glutamate to glutamine. In addition, the glutamate transporter expression in the periphery may also be involved in paracrine cell communication (see below). One exception to this is the localization of GLAST in membranes of supporting cells in the organ of Corti of the inner ear, where this transporter likely contributes to the removal of glutamate from the extracellular space following synaptic release (Furness and Lehre 1997; Furness et al. 2002).

Our results indicate that GLAST may be involved in the glutamate homeostasis in epithelial cell layers. The distribution of GLAST in the epithelial tissues is reminiscent of the distribution of the water channel aquaporin-3 (AQP3) (Matsuzaki et al. 1999). Like AQP3, GLAST is expressed in basolateral membranes of the transitional epithelium in kidney, ureter, urinary bladder, and urethra. In stratified portions of this epithelium, GLAST, like AQP3, is expressed in the basal most layer away from the urinary lumen, suggesting that its role is likely related to the uptake of glutamate from the blood side into the epithelial cells for nourishment, and not to absorb glutamate from the urine. Similarly, in the tongue, GLAST is expressed in the basal most cell layer of the epithelium, suggesting a role in nourishment of the epithelial cells. GLAST expression has also been demonstrated in basal cells of rat taste buds (Lawton et al. 2000). In the ovary, the expression of GLAST by epithelial cells in the corpus luteum and by theca cells may suggest a role in the production of sex hormones. Apart from some GLT-1-like immunoreactivities in the tongue epithelium, GLT-1 was not observed in epithelial cells.

Another primary expression pattern of GLAST is in macrophage-like cells. A number of studies have reported the expression of GLAST in human microglial cells and macrophages under various conditions (Noda et al. 1999; Rimaniol et al. 2000, 2001; van Landeghem et al. 2001; Chretien et al. 2002; Kugler and Schmitt 2003). Under culture conditions, though, GLAST expression in microglia as assayed by PCR analysis was low (Kondo et al. 1995). In the present study, we show GLAST expression by cells in thymus, spleen, and lymph nodes. Some of these GLAST-positive cells have dendritic morphology suggesting that these cells are antigen-presenting cells, possibly of the macrophage lineage. The precise identity of these cells remains to be elucidated by co-staining with cell type specific markers.
Both GLAST and GLT-1 expressions were found in certain lymphocyte populations that did not appear to overlap.

Other areas of observed GLAST expression include fat cells and interstitial cells in connective tissue, where glutamate uptake is likely required for an energy source or metabolic precursor. Further, we observed GLASTlike immunostaining in the capsules of urinary bladder, ovary, heart (not shown), and spleen, reminiscent of its expression in brain meninges (Berger and Hediger 2000). The specificity of the capsular staining could not be confirmed by the presence of GLAST mRNA labeling, possibly due to lack of detection sensitivity in the relatively thin capsule cells. If confirmed, the role of GLAST expression by these capsules may possibly be related to the use of glutamate as an osmolyte (Wagenfeld et al. 2002).

In contrast to GLAST, GLT-1 appears to have a predominant expression in glandular tissue, such as the mammary or the lacrimal glands. In the mammary gland, a previous study has found expression of both GLAST and GLT-1 mRNA and protein (MartinezLopez et al. 1998). The precise cellular expression was not determined, but it was found that the expression of GLT-1 was constant in the physiological situations studied, whereas GLAST expression was down-regulated by fasting and up-regulated after refeeding. GLAST was also reduced after weaning for $24 \mathrm{~h}$ and returned to control values after resuckling. Our findings of GLT-1 expression by glandular cells and GLAST expression by interstitial, connective tissue cells is in agreement with these previous findings since we only examined mammary glands from non-nursing mothers.

In the salivary glands, expression for both transporters was observed. In the submandibular and parotid glands, GLAST was present in the basolateral membranes of the acini, whereas, GLT-1 was expressed primarily in the striated and glandular ducts in the submandibular gland, and in the striated ducts and basal acinar membranes in parotid gland. These localizations suggest that glutamate transport is involved in the generation of saliva. GLT-1 and GLAST both co-transport three $\mathrm{Na}$ ions, and counter transport one $\mathrm{K}$ ion during glutamate uptake (Kanai and Hediger 2004). The strong expression of GLT-1 protein in the luminal surface of glandular ducts may suggest that active glutamate transport from the lumen contributes to the $\mathrm{Na}$ reabsorption and the $\mathrm{K}$ secretion that is occurring in the ducts to create hypotonic saliva (Nauntofte 1992). In the acinar membranes, expression of GLT-1 and GLAST may allow the accumulation of glutamate and the synthesis of glutamate-rich proteins in the salivary glands (Mirels et al. 1990).

A major function of the normal prostate gland is to secrete large amounts of citrate (Costello and Franklin 2002). The prostate epithelial cells have adapted a specialized metabolic process of "net citrate production" which uses aspartate as a source for oxalacetate, a pre- 
requisite for the synthesis of citrate. The basolateral membrane of these epithelial cells possesses high-affinity, androgen-regulated glutamate/aspartate transport activity (Lao et al. 1993). Recently, EAAC1 has been identified as one glutamate transporter responsible for this aspartate transport (Franklin et al. 2006). Our data suggest that GLAST also contributes to the basolateral aspartate transport in prostate (Fig. 2f).

In the liver, GLT-1 mRNA and protein was strongly expressed by perivenous hepatocytes. This finding is in agreement with a recent study that demonstrated similar GLT-1 immunostaining in perivenous hepatocytes and an upregulation of GLT-1 by activation of the betacatenin (Cadoret et al. 2002). The authors of this study have suggested that GLT-1 may be involved in the proliferative response of the liver to beta-catenin by providing glutamate to the cell as a precursor for glutamine. An increase in GLT-1 expression in liver has also been shown in growing versus non-growing lambs (Howell et al. 2003).

Together with the glutamate transporter EAAC1, GLT-1 likely contributes to the interorgan glutamine flux. All cells require glutamine as a nitrogen donor as well as an energy source for cell-specific functions (Welbourne et al. 2001). Muscle generates a major portion of the total body pool of free amino acids while the liver is the site of the urea cycle for disposal of excessive nitrogenous waste. Free amino acids, in particular glutamine, are released from muscle into the blood. In the liver, periportal hepatocytes absorb glutamine and then ammonia is liberated with urea production (Hediger and Welbourne 1999). A sinusoidal glutamate exit mechanism releases glutamate, serving as a major source of circulating glutamate. Glutamate may be re-captured by glutamate transporter GLT-1 located in the downstream perivenous hepatocytes (Fig. 5c, d). Inside these cells, glutamate will be converted to glutamine via glutamine synthetase. Glutamine will then be released into the blood as part of the interorgan glutamine flux. The kidneys also partially contribute toward the disposal of excessive nitrogen waste: filtered glutamine may be converted to glutamate either by the phosphate-independent glutaminase (PIG) at the luminal surface, coupled to absorption of glutamate by EAAC1 (Shayakul et al. 1997; Hediger 1999), or by the intracellular phosphate-dependent glutaminase. Both reactions produce ammonia, which is excreted by the kidneys.

To summarize, our screen of peripheral glutamate transporter expression has revealed widespread localization for GLAST and GLT-1. Although expressed by the same astrocytes in the brain, GLAST and GLT-1 have mostly non-overlapping distribution in peripheral cells, and are likely to contribute to a number of peripheral functions.

Acknowledgment We thank Niels Christian Danbolt from the University of Oslo, Norway for providing the antibodies against GLT-1 and GLAST.

\section{Reference}

Arriza JL, Fairman WA, Wadiche JI, Murdoch GH, Kavanaugh MP, Amara SG (1994) Functional comparisons of three glutamate transporter subtypes cloned from human motor cortex. J Neurosci 14:5559-5569

Berger UV, Hediger MA (1998) Comparative analysis of glutamate transporter expression in rat brain using differential double in situ hybridization. Anat Embryol (Berl) 198:13-30

Berger UV, Hediger MA (2000) Distribution of the glutamate transporters GLAST and GLT-1 in rat circumventricular organs, meninges, and dorsal root ganglia. J Comp Neurol 421:385-399

Berger UV, Hediger MA (2001) Differential distribution of the glutamate transporters GLT-1 and GLAST in tanycytes of the third ventricle. J Comp Neurol 433:101-114

Cadoret A, Ovejero C, Terris B, Souil E, Levy L, Lamers WH, Kitajewski J, Kahn A, Perret C (2002) New targets of betacatenin signaling in the liver are involved in the glutamine metabolism. Oncogene 21:8293-8301

Chen W, Mahadomrongkul V, Berger UV, Bassan M, DeSilva T, Tanaka K, Irwin N, Aoki C, Rosenberg PA (2004) The glutamate transporter GLT1a is expressed in excitatory axon terminals of mature hippocampal neurons. J Neurosci 24:11361148

Chretien F, Vallat-Decouvelaere AV, Bossuet C, Rimaniol AC, Le Grand R, Le Pavec G, Creminon C, Dormont D, Gray F, Gras G (2002) Expression of excitatory amino acid transporter-2 (EAAT-2) and glutamine synthetase (GS) in brain macrophages and microglia of SIVmac251-infected macaques. Neuropathol Appl Neurobiol 28:410-417

Costello LC, Franklin RB (2002) Testosterone and prolactin regulation of metabolic genes and citrate metabolism of prostate epithelial cells. Horm Metabol Res 34:417-424

Franklin RB, Zou J, Yu Z, Costello LC (2006) EAAC1 is expressed in rat and human prostate epithelial cells; functions as a highaffinity L-aspartate transporter; and is regulated by prolactin and testosterone. BMC Biochem 7:10

Furness DN, Hulme JA, Lawton DM, Hackney CM (2002) Distribution of the glutamate/aspartate transporter GLAST in relation to the afferent synapses of outer hair cells in the guinea pig cochlea. J Assoc Res Otolaryngol 3:234-247

Furness DN, Lehre KP (1997) Immunocytochemical localization of a high-affinity glutamate-aspartate transporter, GLAST, in the rat and guinea-pig cochlea. Eur J Neurosci 9:1961-1969

Haugeto O, Ullensvang K, Levy LM, Chaudhry FA, Honore T, Nielsen M, Lehre KP, Danbolt NC (1996) Brain glutamate transporter proteins form homomultimers. J Biol Chem 271:27715-27722

Hediger MA (1999) Glutamate transporters in kidney and brain. Am J Physiol 277:F487-F492

Hediger MA, Welbourne TC (1999) Introduction: glutamate transport, metabolism, and physiological responses. Am J Physiol 277:F477-F480

Howell JA, Matthews AD, Swanson KC, Harmon DL, Matthews JC (2001) Molecular identification of high-affinity glutamate transporters in sheep and cattle forestomach, intestine, liver, kidney, and pancreas. J Anim Sci 79:1329-1336

Howell JA, Matthews AD, Welbourne TC, Matthews JC (2003) Content of ileal EAAC1 and hepatic GLT-1 high-affinity glutamate transporters is increased in growing vs. nongrowing lambs, paralleling increased tissue D- and L-glutamate, plasma glutamine, and alanine concentrations. J Anim Sci 81:1030 1039

Kanai Y, Hediger MA (2004) The glutamate/neutral amino acid transporter family SLC1: molecular, physiological and pharmacological aspects. Pflugers Arch 447:469-479

Kawakami H, Tanaka K, Nakayama T, Inoue K, Nakamura S (1994) Cloning and expression of a human glutamate transporter. Biochem Biophys Res Commun 199:171-176 
Kirschner MA, Copeland NG, Gilbert DJ, Jenkins NA, Amara SG (1994) Mouse excitatory amino acid transporter EAAT2: isolation, characterization, and proximity to neuroexcitability loci on mouse chromosome 2. Genomics 24:218-224

Kondo K, Hashimoto H, Kitanaka J, Sawada M, Suzumura A, Marunouchi T, Baba A (1995) Expression of glutamate transporters in cultured glial cells. Neurosci Lett 188:140-142

Kugler P, Schmitt A (2003) Complementary neuronal and glial expression of two high-affinity glutamate transporter GLT1/ EAAT2 forms in rat cerebral cortex. Histochem Cell Biol 119:425-435

Lao L, Franklin RB, Costello LC (1993) High-affinity L-aspartate transporter in prostate epithelial cells that is regulated by testosterone. Prostate 22:53-63

Lawton DM, Furness DN, Lindemann B, Hackney CM (2000) Localization of the glutamate-aspartate transporter, GLAST, in rat taste buds. Eur J Neurosci 12:3163-3171

Lehre KP, Levy LM, Ottersen OP, Storm-Mathisen J, Danbolt NC (1995) Differential expression of two glial glutamate transporters in the rat brain: quantitative and immunocytochemical observations. J Neurosci 15:1835-1853

Li HS, Niedzielski AS, Beisel KW, Hiel H, Wenthold RJ, Morley BJ (1994) Identification of a glutamate/aspartate transporter in the rat cochlea. Hear Res 78:235-242

Martinez-Lopez I, Garcia C, Barber T, Vina JR, Miralles VJ (1998) The L-glutamate transporters GLAST (EAAT1) and GLT-1 (EAAT2): expression and regulation in rat lactating mammary gland. Mol Membr Biol 15:237-242

Mason DJ (2004) The role of glutamate transporters in bone cell signalling. J Musculoskelet Neuronal Interact 4:128-131

Mason DJ, Suva LJ, Genever PG, Patton AJ, Steuckle S, Hillam RA, Skerry TM (1997) Mechanically regulated expression of a neural glutamate transporter in bone: a role for excitatory amino acids as osteotropic agents? Bone 20:199-205

Matsuzaki T, Suzuki T, Koyama H, Tanaka S, Takata K (1999) Water channel protein AQP3 is present in epithelia exposed to the environment of possible water loss. J Histochem Cytochem 47:1275-1286

Matthews JC, Beveridge MJ, Malandro MS, Rothstein JD, Campbell-Thompson M, Verlander JW, Kilberg MS, Novak DA (1998) Activity and protein localization of multiple glutamate transporters in gestation day 14 vs. day 20 rat placenta. Am J Physiol 274:C603-C614
Mirels L, Kopec L, Yagil C, Dickinson DP, Dziejman M, Tabak LA (1990) Expression of glutamine/glutamic acid-rich proteins in rat submandibular glands. Arch Oral Biol 35:1-5

Nauntofte B (1992) Regulation of electrolyte and fluid secretion in salivary acinar cells. Am J Physiol 263:G823-G837

Noda M, Nakanishi H, Akaike N (1999) Glutamate release from microglia via glutamate transporter is enhanced by amyloidbeta peptide. Neuroscience 92:1465-1474

Redecker P, Kreutz MR, Bockmann J, Gundelfinger ED, Boeckers TM (2003) Brain synaptic junctional proteins at the acrosome of rat testicular germ cells. J Histochem Cytochem 51:809-819

Redecker P, Pabst H (2000) Immunohistochemical study of the glutamate transporter proteins GLT-1 and GLAST in rat and gerbil pineal gland. J Pineal Res 28:179-184

Rimaniol AC, Haik S, Martin M, Le Grand R, Boussin FD, Dereuddre-Bosquet N, Gras G, Dormont D (2000) Na+-dependent high-affinity glutamate transport in macrophages. J Immunol 164:5430-5438

Rimaniol AC, Mialocq P, Clayette P, Dormont D, Gras G (2001) Role of glutamate transporters in the regulation of glutathione levels in human macrophages. Am J Physiol Cell Physiol 281:C1964-C1970

Shashidharan P, Wittenberg I, Plaitakis A (1994) Molecular cloning of human brain glutamate/aspartate transporter II. Biochim Biophys Acta 1191:393-396

Shayakul C, Kanai Y, Lee WS, Brown D, Rothstein JD, Hediger MA (1997) Localization of the high-affinity glutamate transporter EAAC1 in rat kidney. Am J Physiol 273:F1023-F1029

Tanaka K (1993) Expression cloning of a rat glutamate transporter. Neurosci Res 16:149-153

Utsunomiya-Tate N, Endou H, Kanai Y (1997) Tissue specific variants of glutamate transporter GLT-1. FEBS Lett 416:312-316

van Landeghem FK, Stover JF, Bechmann I, Bruck W, Unterberg A, Buhrer C, von Deimling A (2001) Early expression of glutamate transporter proteins in ramified microglia after controlled cortical impact injury in the rat. Glia 35:167-179

Wagenfeld A, Yeung $\mathrm{CH}$, Lehnert W, Nieschlag E, Cooper TG (2002) Lack of glutamate transporter EAAC1 in the epididymis of infertile c-ros receptor tyrosine-kinase deficient mice. J Androl 23:772-782

Welbourne T, Routh R, Yudkoff M, Nissim I (2001) The glutamine/glutamate couplet and cellular function. News Physiol Sci16:157-160 